\title{
Ultrafiltration Tandem Mass Spectrometry of Estrogens for Characterization of Structure and Affinity for Human Estrogen Receptors
}

\author{
Yongkai Sun, Chungang Gu, Xuemei Liu, Wenzhong Liang, Ping Yao, \\ Judy L. Bolton, and Richard B. van Breemen \\ Department of Medical Chemistry and Pharmacognosy, The University of Illinois College of Pharmacy, \\ Chicago, Illinois, USA
}

\begin{abstract}
Although hormone replacement therapy (HRT) is used by post-menopausal women for the relief of menopausal symptoms and the potential reduction of osteoporosis, HRT also increases their risk of Alzheimer's disease, stroke, breast cancer, and endometrial cancer. Since the majority of these effects are associated primarily with estrogen binding to only one of the estrogen receptors (ER), new assays are needed that can more efficiently evaluate ER-binding and identify ligands selective for ER- $\alpha$ and ER- $\beta$. High performance liquid chromatographytandem mass spectrometry (LC-MS-MS) was combined with ultrafiltration as a new method to investigate the relative binding of compounds to the ERs and to evaluate the structures of these estrogens. Mixtures of estradiol and six equine estrogens, including equilin, equilenin, 8,9 -dehydroestrone, and their $17 \beta$-hydroxyl derivatives, were assayed simultaneously to determine their relative binding to human ER- $\alpha$ and ER- $\beta$. Estrogens containing a $17 \beta-\mathrm{OH}$ group were found to have higher relative affinities for the estrogen receptors than their ketone analogs. In addition, $17 \beta$-EN showed selectivity for binding to ER- $\beta$ over ER- $\alpha$. The results were compared to the $\mathrm{IC}_{50}$ values obtained by using a conventional radiolabled estradiol competitive binding assay. Finally, the utility of negative ion electrospray tandem mass spectrometry for the unambiguous identification of these estrogen isomers was investigated. Several characteristic recyclization pathways during tandem mass spectrometry were identified, which might be useful for distinguishing related estrogens. (J Am Soc Mass Spectrom 2005, 16, 271-279) @ 2004 American Society for Mass Spectrometry
\end{abstract}

$\mathrm{E}$ strogens regulate gene expression by binding to intracellular estrogen receptors (ER- $\alpha$ or ER- $\beta$ ), and then to the estrogen-responsive element (ERE) in DNA. The ER-DNA complex modulates the transcription of estrogen-regulated target genes and influences cell growth and differentiation [1,2]. The two subtypes, ER- $\alpha$ and ER- $\beta$, are different from each other in distribution and ligand specificity [3, 4]. Most of ER- $\alpha$ is localized in the uterus, and small amounts are present in ovaries, testes, skin, and gut. ER- $\beta$ occurs at high levels in fetal ovaries, testes, adrenals, and spleen [5], and both ER- $\alpha$ and ER- $\beta$ are expressed in the human central nervous system, breast, bone, and cardiovascular tissue [6]. During menopause, women often experience vasomotor symptoms (e.g., hot flashes) and other sequelae due to low levels of estrogens [7]. Hormone replacement therapy (HRT) may be used to reduce these symptoms and perhaps even reduce the postmenopausal risk of certain age-related disorders such as osteoporosis [8, 9]. Premarin (Wyeth-Ayerst) has be-

Published online December 22, 2004

Address reprint requests to Dr. R. B. van Breemen, Department of Medical Chemistry and Pharmacognosy, The University of Illinois College of Pharmacy, 833 South Wood Street, Chicago, IL 60612, USA. E-mail: breemen@uic.edu come the most widely prescribed HRT and contains the equine estrogens, equilin (EQ), 8,9-dehydroestrone (DHES), equilenin (EN), and the corresponding $17 \beta$ hydroxylated derivatives. However, long-term estrogen replacement therapy increases the risk of developing breast and endometrial cancer [8, 10-12] and has been associated with increased risks of stroke and loss of cognitive function [13, 14].

Since many estrogen analogs that bind to human ER are under investigation as potential new therapeutic agents, there is a need for more efficient assays to evaluate ER-binding and to identify ligands of ER in complex samples such as biological matrices. Although both LC-MS [15-20] and GC-MS [15, 16, 21-23] have been used for the rapid and sensitive identification of estrogens and their metabolites, GC-MS usually requires derivatization which adds to the complexity of sample preparation, increases the time required per analysis, and might introduce artifacts. To eliminate the need for sample derivatization, we developed a method based on LC-MS-MS. From among the solution-phase ionization methods that have been reported for the mass spectrometric analysis of estrogens, such as fast atom bombardment (FAB) [24, 25], atmospheric pressure chemical ionization (APCI) [15, 19], and electrospray $[15,16,20,25,26]$, we selected electro- 


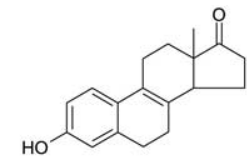

8,9-Dehydroestrone (DHES)

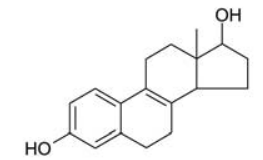

17ß-8,9-Dehydroestrone (17 $\beta$-DHES)
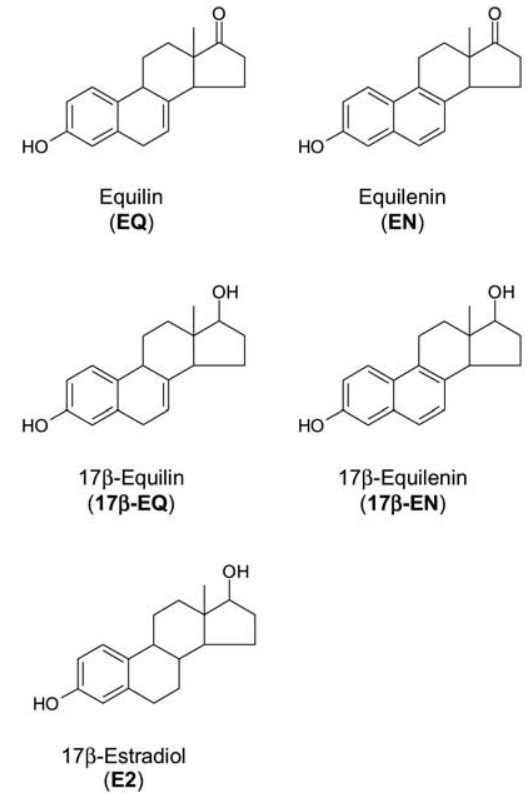

Figure 1. Structures of the estrogens used during this investigation.

spray ionization. Since most investigations of the mass spectrometric fragmentation pathways of estrogens have concerned primarily estrone (E1), estradiol (E2), estriol (E3), and 17 $\alpha$-ethylestradiol (EE2) [15, 16, 20, 23, 26], additional tandem mass spectrometric analyses of a wider variety of estrogen analogs used for HRT were carried out in order to provide a more complete profile of estrogen fragmentation patterns for structural characterization.

LC-MS-MS was combined with ultrafiltration to investigate the binding of ligands to estrogen receptors. Previously in our laboratory, ultrafiltration mass spectrometry has been used for the screening of combinatorial libraries and natural product extracts in order to identify ligands for adenosine deaminase [27, 28], dihydrofolate reductase [29], cyclooxygenase-2 [30], and ER- $\beta$ [31]. In the present study, ultrafiltrationLC-MS-MS was used to screen a mixture of seven estrogens in order to determine simultaneously their relative binding to ER- $\alpha$ and ER- $\beta$ under the conditions of the assay. The estrogens included E2 and six equine estrogens; EQ, EN, 8,9-dehydroestrone (DHES), and their 17 $\beta$-hydroxyl derivatives (Figure 1). This information is being used in our on-going studies for the correlation of estrogen structure with binding.

\section{Experimental}

\section{Chemicals and Reagents}

All organic solvents were HPLC grade or better and were purchased from Fisher (Hanover Park, IL). E2 was purchased from Sigma (St. Louis, MO), and the other six estrogens were synthesized by Dr. Fagen Zhang (University of Illinois College of Pharmacy, Chicago, IL). Human recombinant ER- $\alpha$ and ER- $\beta$ were purchased from Panvera (Madison, $\mathrm{WI}$ ).

\section{Tandem Mass Spectrometry}

Negative ion MS-MS product ion spectra were acquired using a Micromass (Manchester, UK) Quattro II triple quadrupole mass spectrometer equipped with electrospray. Nitrogen was supplied as both nebulizing and drying gas at flow rates of 20 and $450 \mathrm{~L} / \mathrm{h}$, respectively. The drying gas temperature was $150{ }^{\circ} \mathrm{C}$. Argon was used as the collision gas at a pressure of $1.1 \times 10^{-3}$ bar. The electrospray ion source was operated at $80^{\circ} \mathrm{C}$ with a capillary voltage of $-2800 \mathrm{~V}$ and a cone voltage of 55 $\mathrm{V}$. Each estrogen compound $(1 \mu \mathrm{M})$ in methanol/water $(1: 1 ; \mathrm{vol} / \mathrm{vol})$ containing $1 \%$ ammonia was infused into the mass spectrometer at a flow rate of $20 \mu \mathrm{L} / \mathrm{min}$. The collision energies (between 15 and $45 \mathrm{eV}$ ) were optimized for each compound. Abundant product ions were selected for multiple reaction monitoring (MRM) during the LC-MS-MS assay described below.

\section{Binding of Estrogen Analogs to Human Estrogen Receptors using Ultrafiltration LC-MS-MS}

A mixture of estrogen analogs was incubated for $2 \mathrm{~h}$ at room temperature with $100 \mathrm{pmol}$ ER- $\alpha$ or ER- $\beta$ in binding buffer consisting of $50 \mathrm{mM}$ Tris- $\mathrm{HCl}(\mathrm{pH} 7.5), 10 \%$ glycerol, $50 \mathrm{mM} \mathrm{KCl}$, and $1 \mathrm{mM}$ EDTA, in a total volume of $150 \mu \mathrm{L}$. For direct comparison to the conventional estrogen receptor competitive binding assay based on competition of ligands with radiolabeled estradiol (see below), the ${ }^{\circ}$ binding ${ }^{\circ}$ buffer ${ }^{\circ}$ of ${ }^{\circ} \operatorname{Liu}^{\circ}{ }^{\circ} t^{\circ} a{ }^{\circ}{ }^{\circ}[31]^{\circ}$ was $^{\circ}$ also ${ }^{\circ}$ used ${ }^{\circ}$ in ${ }^{\circ}$ one series of experiments, which consisted of $10 \mathrm{mM}$ Tris- $\mathrm{HCl}$ (pH 7.5), 10\% glycerol, $2 \mathrm{mM}$ dithiothreitol, and $1 \mathrm{mg} / \mathrm{mL}$ bovine serum albumin. Identical control incubations in which ER was omitted or denatured ER was substituted for active ER were used to correct for nonspecific binding (adsorption) of estrogens to the ultrafiltration membrane and holder. For the control incubations, ER was denatured by boiling for $10 \mathrm{~min}$. After incubation each mixture was filtered through a Microcon (Millipore, Bedford, MA) YM-30 centrifugal filter containing a regenerated cellulose ultrafiltration membrane with a 30,000 MW cutoff by centrifugation at $10,000 \mathrm{~g}$ for $7 \mathrm{~min}$ at $4{ }^{\circ} \mathrm{C}$. The filter was washed three times by centrifugation with $150 \mu \mathrm{L}$ aliquots of ammonium acetate buffer ( $\mathrm{pH} 7.5)$ at $4{ }^{\circ} \mathrm{C}$ to remove the unbound compounds. The bound ligands were released by adding $400 \mu \mathrm{L}$ of methanol/water (90:10; vol/vol) followed by centrifugation at 10,000 $\mathrm{g}$ for $10 \mathrm{~min}$. The solvent in the ultrafiltrate was removed under vacuum, and the released ligands were redissolved in $60 \mu \mathrm{L}$ of methanol/water (50:50; vol/vol). Aliquots $(30 \mu \mathrm{L})$ of this reconstituted ligand solution were analyzed using LCMS-MS, which consisted of a Waters (Milford, MA) 2690 HPLC system coupled to a Quattro II electrospray triple quadrupole mass spectrometer. HPLC separations were carried out using a Waters Xterra MS $\mathrm{C}_{18}(3.5 \mu \mathrm{m}, 2.1 \times$ $100 \mathrm{~mm}$ ) HPLC column. The mobile phase consisted of $35 \%$ aqueous acetonitrile for $4 \mathrm{~min}$ at $0.2 \mathrm{~mL} / \mathrm{min}$ followed by an 11 min linear gradient from $35-50 \%$ acetonitrile with post-column addition of $0.1 \%$ ammonia in 
Table 1. Precursor/product ion pairs and collision energies used for multiple reaction monitoring of estrogens

\begin{tabular}{lcc}
\hline Compound & $\begin{array}{c}\text { Precursor ion } \rightarrow \text { Product ion } \\
(\mathrm{m} / \mathrm{z})\end{array}$ & $\begin{array}{c}\text { Collision energy } \\
(\mathrm{eV})\end{array}$ \\
\hline \hline EN & $265 \rightarrow 221$ & 30 \\
EQ & $267 \rightarrow 143$ & 30 \\
DHES & $267 \rightarrow 171$ & 30 \\
$17 \beta$-EN & $267 \rightarrow 181$ & 30 \\
$17 \beta$-EQ & $269 \rightarrow 267$ & 35 \\
$17 \beta$-DHES & $269 \rightarrow 171$ & 30 \\
E2 & $271 \rightarrow 183$ & 40 \\
\hline
\end{tabular}

methanol/water (50:50, vol/vol) at $15 \mu \mathrm{L} / \mathrm{min}$. During LC-MS-MS, the electrospray ion source was operated at $150{ }^{\circ} \mathrm{C}$ in negative ion mode at a cone voltage of $55 \mathrm{~V}$. The ion transitions used for MRM and the corresponding collision energies for collision-induced dissociation (CID) are ${ }^{\circ}$ summarized ${ }^{\circ}{ }^{\circ}{ }^{\circ}$ able $^{\circ} 1$. The $^{\circ}$ dwell ${ }^{\circ}$ time ${ }^{\circ}$ was $0.20^{\circ}$ s $^{\circ}$ for each MRM channel.

\section{Estrogen Receptor Competitive-Binding Assays}

The $^{\circ}$ procedure $^{\circ}$ of $^{\circ}$ Obourn $^{\circ}$ et $^{\circ}$ al. $^{\circ}[32]^{\circ}$ was $^{\circ}$ used $^{\circ}$ with minor ${ }^{\circ}$ modifications ${ }^{\circ} \mathrm{as}^{\circ} \mathrm{described}^{\mathrm{b}} \mathrm{y}^{\circ} \mathrm{Liu}^{\circ} \mathrm{et}^{\circ} \mathrm{al} .{\text { [ }[31]^{\circ} \text { as }}^{\circ}$ an alternative measurement of estrogen binding to each estrogen receptor. This assay measures binding to ER- $\alpha$ and ER- $\beta$ in terms of competition of ligands with $\left[{ }^{3} \mathrm{H}\right]$-estradiol.

\section{Results and Discussion}

\section{Ultrafiltration LC-MS-MS Analysis of Binding to $E R-\alpha$ and $E R-\beta$}

The HPLC separation of the seven structurally similar estrogens $^{\circ}\left(\text { Figure }^{\circ} 1\right)^{\circ}$ differing $^{\circ}$ primarily $^{\circ}$ by $^{\circ} a^{\circ}$ ketone $^{\circ}$ or hydroxyl group at carbon-17 or unsaturation in the $\mathrm{B}$ ring was challenging. Ultimately, a 15-min separation incorporating an 11-min slow gradient with a standard $\mathrm{C}_{-18}$ reversed phase HPLC column was found to provide $^{\circ}$ baseline $^{\circ}$ separation $^{\circ}$ of $^{\circ}$ all $^{\circ}$ seven $^{\circ}$ compounds $^{\circ}($ Figure 2). In addition, the ${ }^{\circ}$ estrogens ${ }^{\circ}$ could be $^{\circ}$ distinguished using tandem mass spectrometry as discussed below.

Positive and negative ion electrospray ionization were compared for the analysis of the estrogen analogs. Since the deprotonated molecules of these compounds during negative ion electrospray were more abundant than the corresponding protonated molecules in positive ion mode, and since the fragmentation patterns of these estrogen analogs were distinctly different in negative mode only, negative ion electrospray ionization was used for all subsequent LC-MS-MS analyses. The $[\mathrm{M}-\mathrm{H}]^{-}$ions of each of the seven estrogens were selected as the precursors for CID, and the most abundant fragment ions produced during CID were identified for use during MRM. The precursor and product ion pairs for MRM and optimum CID energy for each estrogen ${ }^{\circ} \operatorname{analog}^{\circ} \operatorname{are}^{\circ}$ summarized $^{\circ}$ in $^{\circ}$ Table $^{\circ} 1$.
Even though some compounds had the same molecular weight, e.g., 17 $\beta$-EN, EQ, and DHES (MW 268), or $17 \beta$-EQ and 17 $\beta$-DHES (MW 270), they produced unique product ion mass spectra during negative ion electrospray tandem mass spectrometry as well as eluting at different retention times during HPLC. As a result, high selectivity was obtained in the analysis of these seven compounds during LC-MS-MS. Standard curves for the seven estrogens were obtained using LC-MS-MS and showed excellent linearity from 0.2-30 pmol (amount injected onto the LC-MS-MS system) with correlation coefficients $\left(r^{2}\right)$ exceeding $>0.996$. Although not needed for this application, in which the relative binding of estrogens in a mixture was being compared, the use of an internal standard would probably have improved the reproducibility of these assays.

Unlike our previously reported applications of ultrafiltration mass spectrometric screening for drug discovery $^{\circ}[27-31]$, the $^{\circ}$ present $^{\circ} \operatorname{method}^{\circ}$ was $^{\circ}{ }^{\circ}$ esigned ${ }^{\circ}$ to $^{\circ}$ characterize the relative binding of a mixture of estrogens to human ER- $\alpha$ and ER- $\beta$. The adsorption of ligands to the ultrafiltration membrane and nonspecific binding to the receptors were determined by carrying out identical control incubations without receptor or with denatured receptor in the solution. No differences were observed between the controls without receptor and those with denatured receptor. Since nonspecific binding to the estrogen receptor was not detected, the difference in the LC-MS-MS peak area for a ligand detected in the native

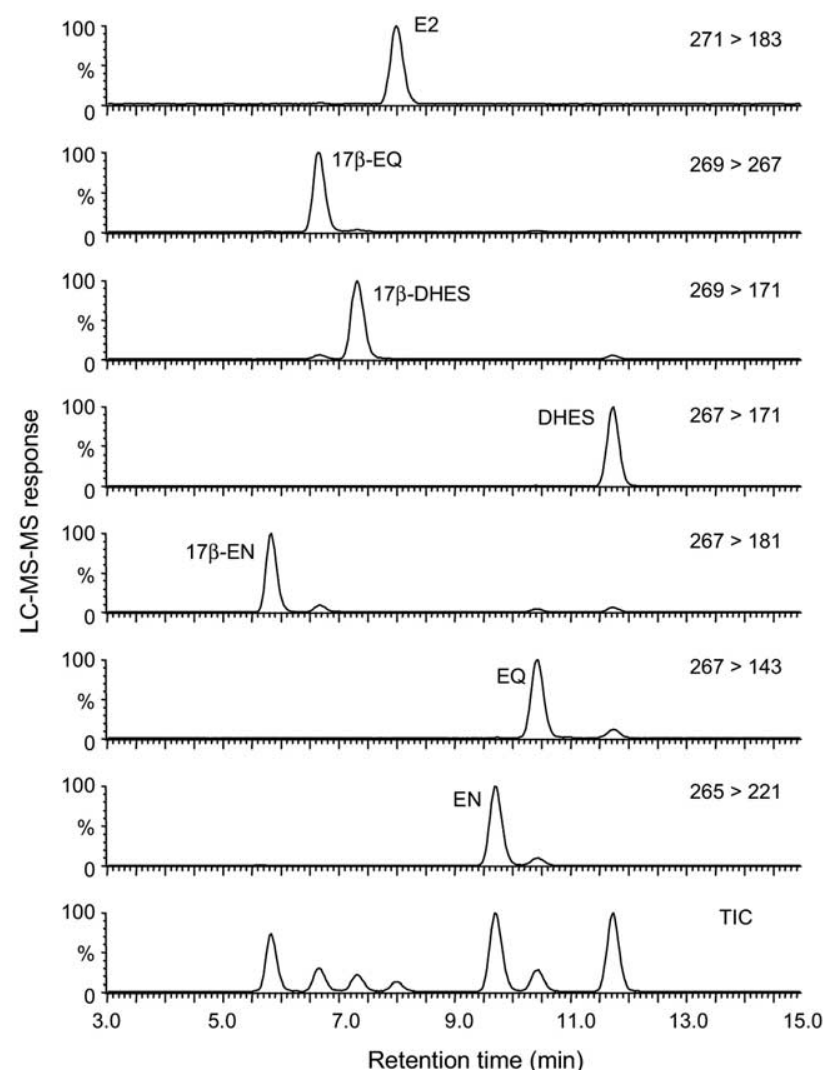

Figure 2. LC-MS-MS of seven estrogen analogues. 
(a)

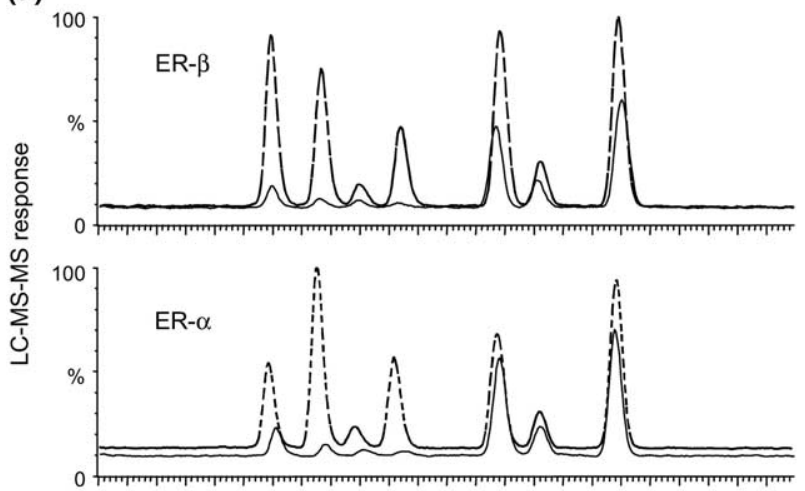

(b)

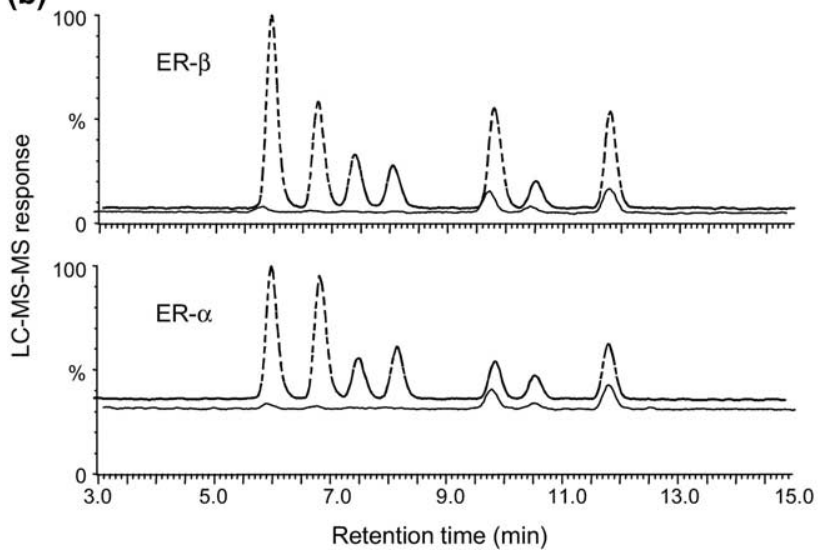

Figure 3. Ultrafiltration LC-MS-MS screening of (a) $1.0 \mu \mathrm{M}$ and (b) ${ }^{\circ} 0.2^{\circ} \mu \mathrm{M}$, equimolar ${ }^{\circ}$ mixtures ${ }^{\circ}$ of ${ }^{\circ}$ the ${ }^{\circ}$ estrogens ${ }^{\circ}$ shown ${ }^{\circ}$ in ${ }^{\circ}$ Figure 1 incubated ${ }^{\circ}$ with $0.667^{\circ} \mu \mathrm{M}^{\circ} \mathrm{ER}-\alpha^{\circ}$ or ${ }^{\circ} \mathrm{ER}-\beta$. The $^{\circ} \mathrm{Control}{ }^{\circ}$ incubations (solid lines) containing denatured ER were used to correct for nonspecific binding and adsorption of the sample to the ultrafiltration apparatus. Enhancement of HPLC peak areas in the experimental incubations (dashed lines) indicate specific binding of ligands to ER and were used to calculate the enhancement factors ${ }^{\circ}$ shown $^{\circ}$ in $^{\circ}$ Table $^{\circ} 2$.

ER experiment and in the corresponding control, without protein or with denatured protein, corresponded to specific ${ }^{\circ}$ binding. ${ }^{\circ}$ For $^{\circ}$ example, ${ }^{\circ}$ Figure ${ }^{\circ} 3^{\circ}$ shows ${ }^{\circ}$ typical LC-MS-MS chromatograms of the estrogen mixture acquired for the ultrafiltrates of binding experiments with active and denatured (control) ER- $\alpha$ and ER- $\beta$.

Incubations of ER- $\alpha$ or ER- $\beta(0.667 \mu \mathrm{M})$ were carried out with two different equimolar concentrations of the seven estrogens $(1 \mu \mathrm{M}$ or $0.2 \mu \mathrm{M})$. Exemplary ultrafiltration mass chromatograms for these experiments are shown ${ }^{\circ}$ in ${ }^{\circ}$ Figure ${ }^{\circ} 3 .{ }^{\circ}$ Based ${ }^{\circ}$ on $^{\circ}$ these ${ }^{\circ}$ chromatograms ${ }^{\circ}$ and the standard curves, enrichment factors representing the specific binding of each estrogen to its receptor were obtained by dividing the amount of specific binding, which corresponds to the subfraction of the control signal from those of the experiment, by the original amount of each compound in the incubation solution. All $^{\circ}$ of ${ }^{\circ}$ the ${ }^{\circ}$ enrichment ${ }^{\circ}$ values $^{\circ}$ are ${ }^{\circ}$ shown ${ }^{\circ}{ }^{\circ}{ }^{\circ}$ Table $^{\circ} 2^{\circ}$ and may be used to rank the relative binding affinities of these estrogen analogs.

When the concentration of each estrogen exceeded

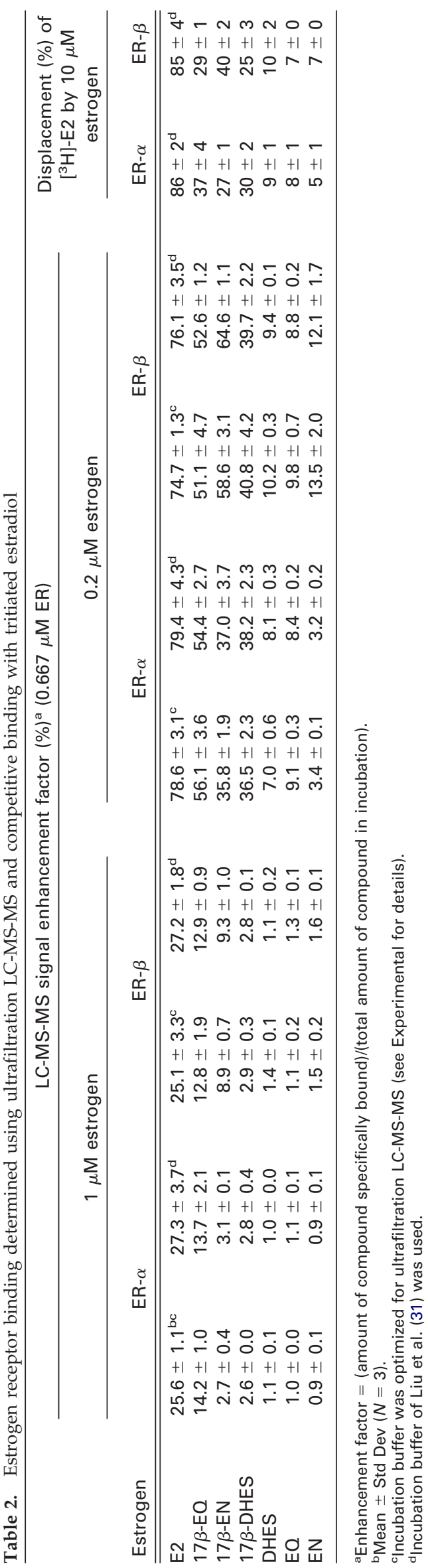


the concentration of the receptor, only the highest affinity estrogens showed specific binding to ER- $\alpha$ and ER- $\beta$ due to competition for receptor sites. The estrogens with the highest affinity for ER- $\alpha$ and ER- $\beta$ were the 17- $\beta$-hydroxyl compounds (17 $\beta$-EQ, $17 \beta$-EN, $17 \beta$ DHES) and estradiol eluting between 5.5 and $8.5 \mathrm{~min}$ (see ${ }^{\circ}$ igure $3 a$ ). ${ }^{\circ}$ When ${ }^{\circ}$ estrogens ${ }^{\circ}$ at $^{\circ}$ the ${ }^{\circ}$ lower ${ }^{\circ}$ concentration were incubated with excess ER, specific binding was observed for all estrogens in the mixture but to different extents reflecting their relative affinities for ER- $\alpha^{\circ}$ and $^{\circ}$ ER- $\beta^{\circ}$ (Figure ${ }^{\circ} 3 b^{\circ}$ and $^{\circ}$ Table $\left.^{\circ} 2\right){ }^{\circ}$ According ${ }^{\circ}$ to the $e^{\circ}$ enrichment ${ }^{\circ}$ factors ${ }^{\circ}$ shown $^{\circ}{ }^{\circ}{ }^{\circ}$ Table $^{\circ} 2^{\circ}$ (at ${ }^{\circ}$ the $0.2^{\circ} \mu \mathrm{M}$ estrogen concentration), the affinity rank order for binding to $\mathrm{ER}-\alpha$ was $\mathrm{E} 2>17 \beta-\mathrm{EQ}>17 \beta$-EN $\cong$ $17 \beta$-DHES $\gg \mathrm{DHES} \cong \mathrm{EQ}>\mathrm{EN}$. The rank order for binding to ER- $\beta$ was slightly different with E2 $>17$ $\beta$-EN $>17 \beta$-EQ $>17 \beta$-DHES $\gg$ DHES $>$ EQ $>$ EN. Only $17 \beta$-EN and EN showed binding selectivity toward ER- $\beta$ compared to ER- $\alpha$.

Two different binding buffers were used for ultrafiltration LC-MS-MS, and the relative affinities of the estrogens for ER- $\alpha$ and ER- $\beta$ varied slightly depending upon the buffer. One binding buffer contained TRIS buffer, glycerol, $\mathrm{KCl}$, and EDTA and was recommended by the supplier of the estrogen receptors. The second binding buffer was that used in the radiolabeled estra-

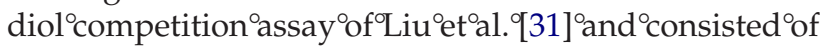
TRIS buffer, glycerol, dithiothreitol, and bovine serum albumin. Since the composition of the buffer was found to affect the relative binding of estrogens to ER- $\alpha$ and ER- $\beta$, and since a goal of this investigation was to validate the new ultrafiltration LC-MS-MS assay for the rank ordering of estrogens by comparison to another validated assay, it was necessary to use identical binding buffers for both assays. A comparison of the data sets for both buffers indicates that the signal enhancement factors obtained using ultrafiltration LC-MS-MS and the radiolabeled estradiol competition buffer were closest to the binding values measured using the estradiol $^{\circ}$ competition $^{\circ} \operatorname{assay}^{\circ}\left(\right.$ Table $\left.^{2}\right)$. However, the . enhance- $^{\circ}$ ment factors showed the same relative order no matter which binding buffer was used. For future assays, we prefer to use the binding buffer recommended by the ER supplier, since this buffer does not contain bovine serum albumin which might compete with the ER for some ligands.

The rank order of the binding of estrogens in an equimolar mixture of estrogens to ER- $\alpha$ and ER- $\beta$ determined using ultrafiltration LC-MS-MS was identical to that obtained using the conventional radiolabeled estradiol competition assay. Competitive binding with $\left[{ }^{3} \mathrm{H}\right]$-estradiol is a widely used method for the quantitative $^{\circ}$ comparison $^{\circ}$ of $^{\circ}$ estrogenic $^{\circ}$ compounds $^{\circ}\left[33\right.$ [ $^{\circ}$ Furthermore, these data indicate that $17 \beta$-EN and $\mathrm{EN}$ are ER- $\beta$ selective, and that the $17 \beta$-hydroxyl compounds have greater affinity for human estrogen receptors than their ketone analogs.

Since all of the compounds screened in this investigation were ligands for $\mathrm{ER}-\alpha$ and $\mathrm{ER}-\beta$, this work shows how ultrafiltration LC-MS-MS may be used to rapidly rank order a directed library of analogs with respect to affinity for a specific target. Our approach is significantly different from others in the literature such as affinity chromatography containing immobilized receptor ${ }^{\circ}[34]^{\circ}$ or $^{\circ}$ antibody ${ }^{\circ}[35]^{\circ}$ and ${ }^{\circ}$ other ${ }^{\circ}$ approaches ${ }^{\circ}$ such as ${ }^{\circ}$ phage-display ${ }^{\circ}$ libraries ${ }^{\circ}[36]^{\circ}$ or ${ }^{\circ}$ ligands ${ }^{\circ}$ immobilized on $^{\circ}$ beads ${ }^{\circ}[37] .{ }^{\circ}$ Unlike $^{\circ}$ these $^{\circ}$ other $^{\circ}$ approaches, ${ }^{\circ}$ ultrafiltration LC-MS-MS allows the receptor and ligand to bind in solution, which avoids potential alterations in their pharmacological and biochemical characteristics that might result from immobilization.

\section{MS-MS of Estrogen Analogs}

During these ultrafiltration LC-MS-MS analyses, tandem mass spectrometry was used to distinguish between closely eluting estrogen analogs. This high level of selectivity was particularly important for the unambiguous determination of EN and EQ which have similar HPLC retention times of approximately 9.7 and $10.4^{\circ} \mathrm{min}$, 'respectively $^{\circ}$ (Figure 2 ). The $^{\circ} \mathrm{CID}^{\circ}$ tandem ${ }^{\circ}$ mass spectra of $[\mathrm{M}-\mathrm{H}]^{-}$ions of all seven of the estrogens used $^{\circ}$ in $^{\circ}$ this $^{\circ}$ study $^{\circ}$ are $^{\circ}$ shown $^{\circ}$ in $^{\circ}$ Figure $^{\circ} 4 .^{\circ}$ During MS-MS of these compounds, the elimination of small neutral molecules from the $[\mathrm{M}-\mathrm{H}]^{-}$precursor ions were commonly observed. These small molecules included $\mathrm{H}_{2}, \mathrm{CH}_{4}$, and $\mathrm{CO}$. The loss of $\mathrm{H}_{2}$ probably occurred from the $\mathrm{B}$ ring, since this process would be stabilized by the formation of conjugated alkenes or an aromatic ring. The loss of $\mathrm{CH}_{4}, \mathrm{CH}_{3} \mathrm{OH}$, or $\mathrm{CO}$ probably occurred from the $\mathrm{D}$ ring and involved the 13-methyl group and the 17-hydroxyl or carbonyl group.

The most abundant fragment ions are consistent with the fragmentation pathway of retrocyclization. Probable sites for estrogen ring cleavage during retrocyclization are suggested in Scheme 1 . In the negative ion electrospray ${ }^{\circ}$ tandem ${ }^{\circ}$ mass $^{\circ}$ spectrum $^{\circ}$ of ${ }^{\circ} 2^{\circ}$ (Figure ${ }^{\circ} 4 a$ ), the formation of abundant product ions of $m / z$ 183, 145, and 143 are consistent with retrocyclization modes 1 and 3 (Scheme 1) combined with loss of $\mathrm{H}_{2}$. Fragmentation pathways for the formation of these product ions are suggested in Scheme 2 . All of these product ions are stabilized by conjugated double bonds and an aromatic ring. Furthermore, these fragmentation pathways are consistent with the tandem mass spectra of the other estrogens. For example, in the tandem mass spectra of EQ and its $17 \beta$-hydroxyl derivatives, the ion of $m / z 143$, but not $m / z 145$, was detected since there is a double bond in the B ring for these compounds. For the same reason, there was an ion of low abundance at $m / z 183$ but an abundant signal at $m / z 181$. Since EN and $17 \beta$-EN contain an aromatic $B$ ring, retrocyclization mode 1 cannot occur for these compounds, and no product ions of $m / z 145$ or 143 were observed. Finally, the ion $m / z 239$ might result from the loss of $\mathrm{CH}_{3} \mathrm{OH}$.

The fragmentation pathways of $17 \beta$-EQ are shown in Scheme 3. The most abundant fragment ion is observed at $m / z 267$ and is probably formed by the loss of $\mathrm{H}_{2}$ from 
(a)

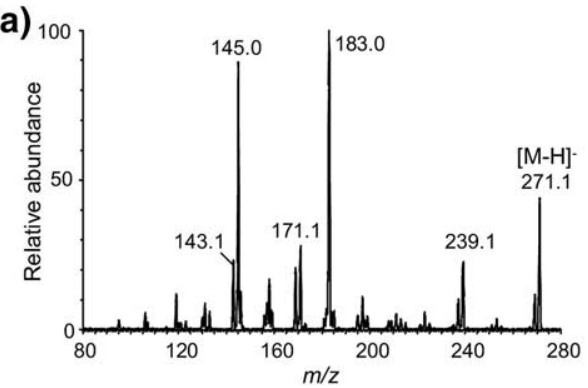

(c)

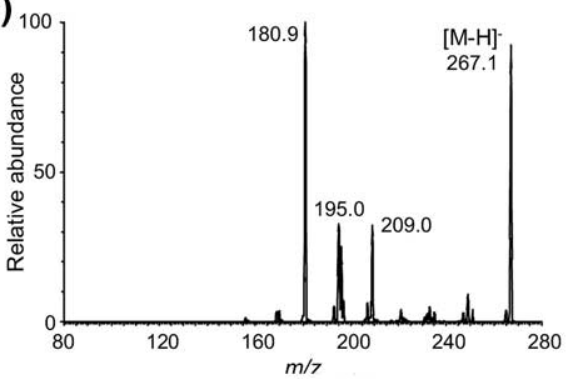

(e)
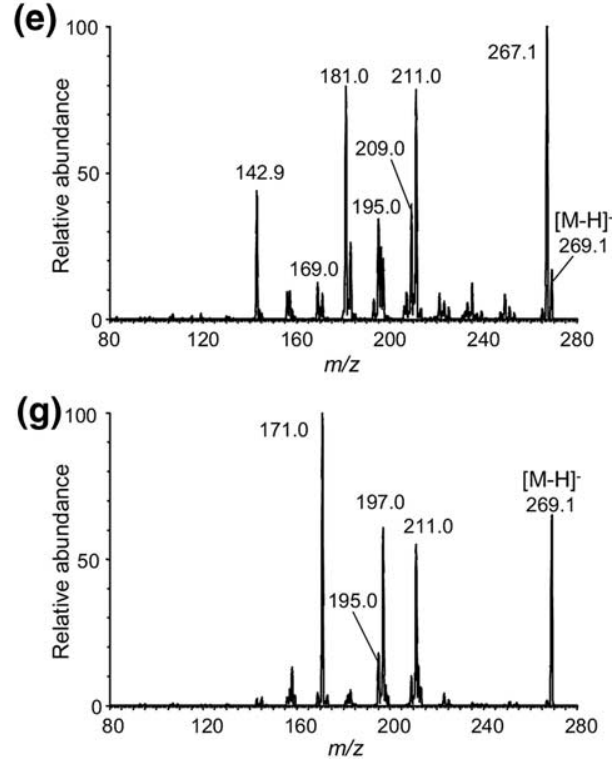

(b)

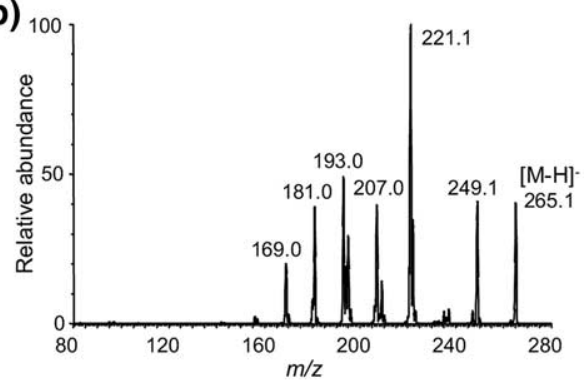

(d)

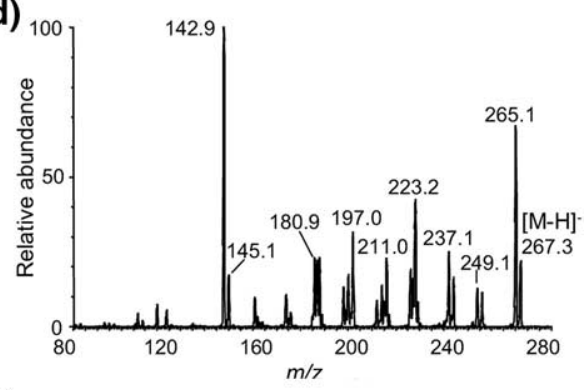

(f) 100

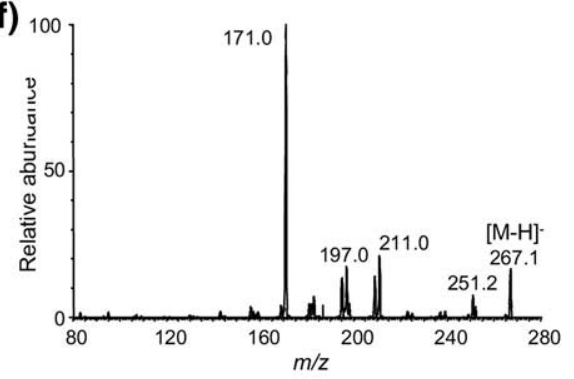

Figure 4. Negative ion electrospray with CID tandem mass spectra of estrogen analogs (a) E2, (b) EN, (c) $17 \beta$-EN, (d) EQ, (e) $17 \beta$-EQ, (f) DHES, and (g) $17 \beta$-DHES.

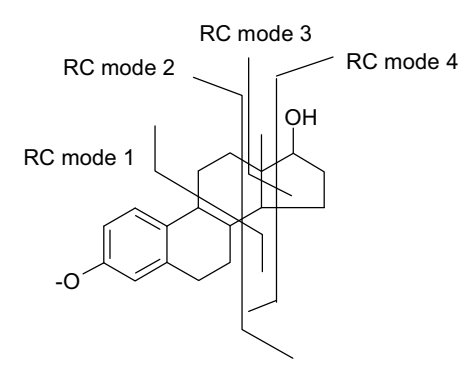

Scheme 1. Proposed recyclization modes of estrogens during negative ion electrospray CID tandem mass spectrometry.

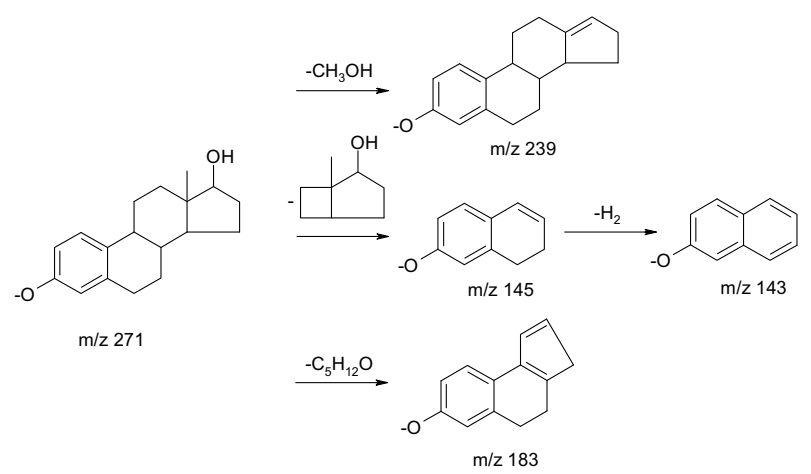

Scheme 2. Proposed fragmentation pathways of the deprotonated molecule of E2. 


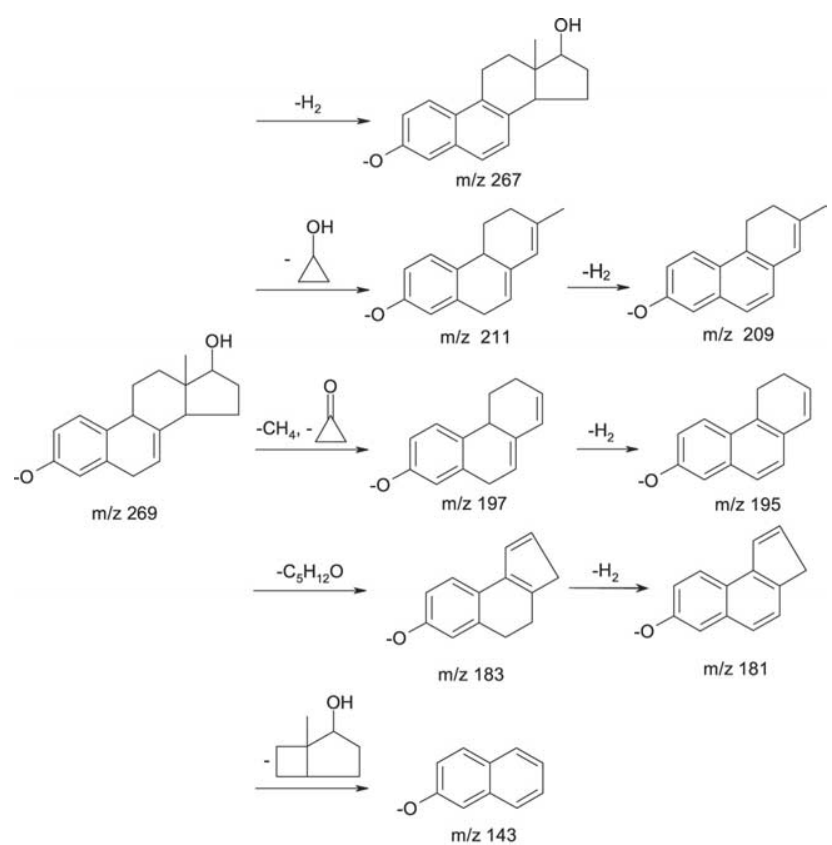

Scheme 3. Proposed fragmentation pathways of the deprotonated molecule of $17 \beta$-EQ.

the $B$ ring to give a stable aromatic ring. Similarly, the abundant ion of $m / z 265$ in the tandem mass spectrum of EQ corresponds to loss of $\mathrm{H}_{2}$. The product ions of $\mathrm{m} / \mathrm{z}$ 183,181 , and 143 result from the retrocyclization modes 1 and 3 and are analogous to those of E2. Unlike E2, $17 \beta$-EQ also produces ions of $m / z 211,209,197$, and 195, which probably were formed through retrocyclization mode 4 . The ion of $m / z 211$ corresponds to retrocyclization mode 4 with loss of cyclopropanol $\left(\mathrm{C}_{3} \mathrm{H}_{6} \mathrm{O}\right)$ from the $[\mathrm{M}-\mathrm{H}]^{-}$ion $(m / z 269)$. The formation of $m / z 197$ is consistent with loss of $\mathrm{CH}_{4}$ followed by elimination of cyclopropanone $\left(\mathrm{C}_{3} \mathrm{H}_{4} \mathrm{O}\right)$. The ions of $\mathrm{m} / z 209$ and 195 are probably formed from $\mathrm{m} / \mathrm{z} 267$ by retrocyclization or from $m / z 211$ and 197 by loss of $\mathrm{H}_{2}$. In addition, a radical ion of $m / z 196$ can be obtained via the same pathway as $\mathrm{m} / \mathrm{z} 195$ except that a methyl radical is eliminated instead of methane. The fragmentation pattern of the

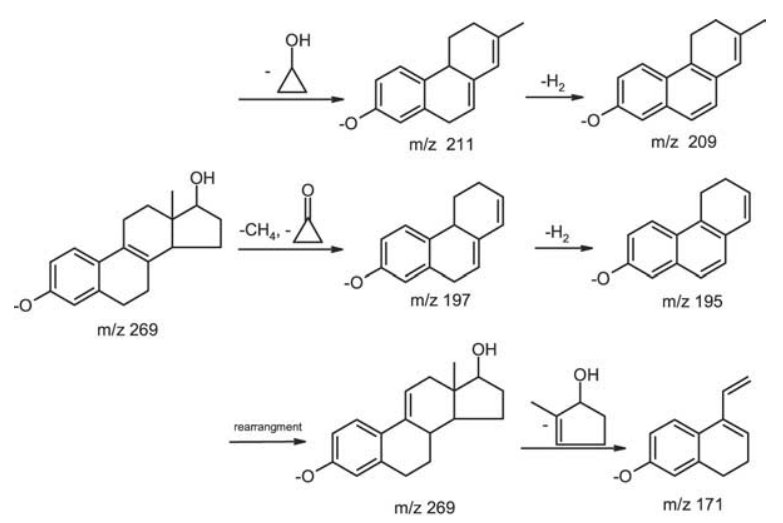

Scheme 4. Proposed fragmentation pathways of the deprotonated molecule of $17 \beta$-DHES.

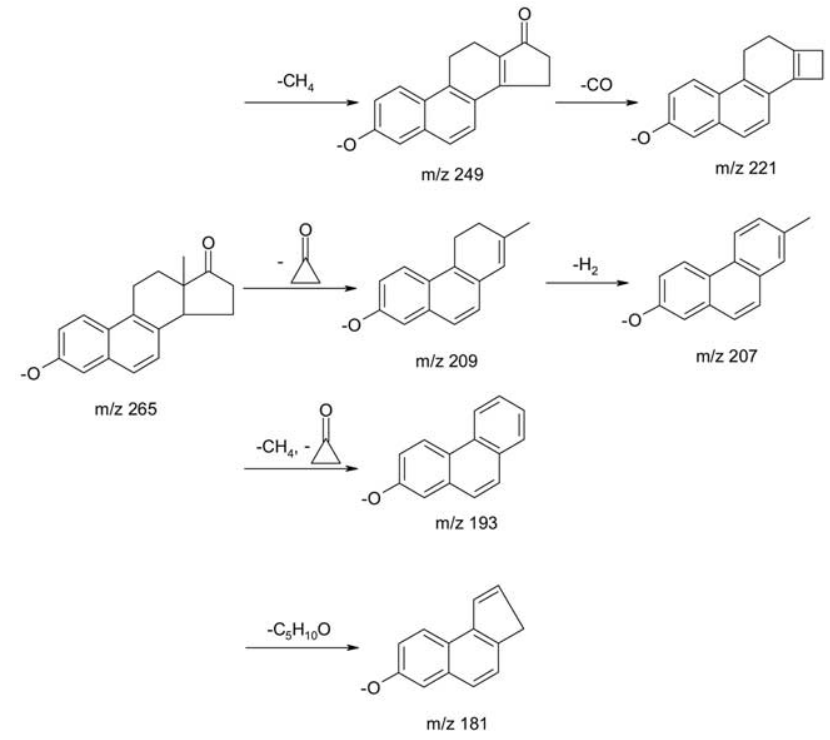

Scheme 5. Proposed fragmentation pathways of the deprotonated molecule of EN.

deprotonated ${ }^{\circ}$ molecule $^{\circ}$ of ${ }^{\circ} 17 \beta$-EN ${ }^{\circ}$ (Figure $\left.4 \mathrm{c}\right)^{\circ}{ }^{\circ}$ si $^{\circ}$ similar to that of $17 \beta$-EQ and is consistent with retrocyclization mode 4 . However, the ions of $\mathrm{m} / \mathrm{z} 145$ and 143 were not detected due to the aromatic B ring as discussed above.

The tandem mass spectrum of the deprotonated molecule $^{\circ}$ of $^{\circ} 17 \beta$-DHES ${ }^{\circ}$ (Figure $\left.{ }^{\circ} 4 \mathrm{~g}\right)^{\circ}$ shows $^{\circ}$ abundant product ions of $m / z 211,209,197$, and 195, and the fragmentation pathway for this estrogen (Scheme 4) is consistent with retrocyclization mode 4 . However, this pattern was quite different from $17 \beta$-EQ because of the different position of the double bond on the B ring. In the case of $17 \beta-\mathrm{EQ}$, the 7,8 -double bond is not conjugated with the aromatic ring, so that $\gamma$ - $\mathrm{H}$ elimination is more probable leading to loss of $\mathrm{H}_{2}$. In comparison, $17 \beta$-DHES has an 8,9 -double bond that is stabilized through conjugation with the aromatic ring. Therefore, the loss of $\mathrm{H}_{2}$ from the $[\mathrm{M}-\mathrm{H}]^{-}$ion is unlikely, and the fragment ion of $\mathrm{m} / \mathrm{z} 267$ is low in abundance. In addition, the position of the double bond in the $\mathrm{B}$ ring also affects the retrocyclization pathway. The tandem mass spectrum of $17 \beta$-DHES also showed fragment ions such as $m / z 171$ which were consistent with retrocyclization mode 2 and a retro-Diels-Alder reaction pathway instead of mode 3 . The $\gamma-\mathrm{H}$ rearrangement probably occurred first followed by the retro-Diels-Alder reaction. Signals at $m / z 171$ and 169 (loss of $\mathrm{H}_{2}$ from $\mathrm{m} / z$ 171) were observed in low abundance in other tandem mass spectra. These unique MS-MS fragmentation pathways distinguished $17 \beta$-DHES from $17 \beta$-EQ as well as DHES from $E Q$, which are two pairs of isomers differing only by the position of a carbon-carbon double bond.

Eliminations of $\mathrm{CH}_{4}$ and $\mathrm{CO}$ were more favorable for the ketone compounds than their hydroxyl derivatives. For example, abundant ions of $\mathrm{m} / \mathrm{z} 249$ and $\mathrm{m} / \mathrm{z} 221$ were detected in the tandem mass spectrum of EN corresponding to $\left[\mathrm{M}-\mathrm{H}-\mathrm{CH}_{4}\right]^{-}$and $\left[\mathrm{M}-\mathrm{H}-\mathrm{CH}_{4}^{-}\right.$ 
$\mathrm{CO}]^{-},{ }^{\circ}$ respectively ${ }^{\circ}\left(\right.$ Figure $\left.^{\circ} 4 \mathrm{~b}\right){ }^{\circ}$ Fragmentation $^{\circ}$ pathways for the formation of the ions of 249 and 221 are shown in Scheme 5. The formation of the 13,14-double bond during elimination of $\mathrm{CH}_{4}$ would be stabilized by conjugation with the carbonyl group in these ketones. In addition, the 13,14-double bond would be conjugated with the double bond in the B-ring. The loss of CO from the ketones was more favorable than from their hydroxyl derivatives, since fewer bonds would need to be formed and broken. Although ions formed by eliminations of $\mathrm{CH}_{4}$ and $\mathrm{CO}$ were more abundant in the ketone estrogen $^{\circ}\left(\text { Figure }^{\circ} 4 \mathrm{~b},{ }^{\circ} \mathrm{d},{ }^{\circ} \mathrm{f}\right)^{\circ}$ than $^{\circ}$ in $^{\circ}$ the ${ }^{\circ} 17 \beta$-hydroxyl derivatives, the retrocyclization fragmentation modes were still observed including retrocyclization mode 1 for EQ and DHES, mode 2 (retro-Diels-Alder fragmentation) for DHES, mode 3 for EQ and EN, and mode 4 for EQ, EN and DHES.

\section{Conclusions}

We have developed a method using ultrafiltration and LC-MS-MS to determine the relative affinities of human and equine estrogens to human ER- $\alpha$ and ER- $\beta$. The application of this method indicates that estrogens containing a $17 \beta-\mathrm{OH}$ moiety have higher affinities for the estrogen receptors than their ketone analogs and that $17 \beta$-EN and EN bind selectively to ER- $\beta$ over ER- $\alpha$. These findings are consistent with the values obtained using a conventional radiolabled estradiol competitive binding assay.

During the development of this ultrafiltration LCMS-MS assay, we investigated the tandem mass spectra of these compounds in order to select suitable fragment ions for MRM. Although either negative or positive ion electrospray ionization produces abundant deprotonated or protonated molecules, respectively, we found that only the deprotonated molecules produced unique as well as abundant fragment ions of the isomeric estrogens. Therefore, we used negative ion electrospray ionization combined with CID and MRM during LCMS-MS for the unique identification and measurement of the estrogens in the ultrafiltrates. While developing this assay and interpreting the tandem mass spectra, we identified and report here various retrocyclization pathways for these estrogens. These fragmentation pathways and various unique fragment ions may be used to distinguish the estrogen isomers unambiguously and should be useful during other investigations of these compounds.

\section{Acknowledgments}

The authors thank Dr. Fagen Zhang for the synthesis of estrogens used in this investigation. This work was funded by NIH grants R01 CA73638 and R24 CA83124 from the National Cancer Institute, and P50 AT00155 provided jointly by the Office of Dietary Supplements, the National Center for Complementary and Alternative Medicine, the Office for Research on Women's Health, and the National Institute of General Medical Sciences. The content is the responsibility of the authors and does not necessarily represent the official views of the sponsors.

\section{References}

1. Gaido, K.W.; Maness, S.C.; Waters, K.M. Exploring the biology and toxicology of estrogen receptor- $\beta$. AIIT Activities 1999, 19, $1-5$.

2. Saegusa, M; Okayasu, I. Changes in expression of estrogen receptors $\alpha$ and $\beta$ in relation to progesterone receptor and pS2 status in normal and malignant endometrium. Jpn. J. Cancer Res. 2000, 91, 510-518.

3. Kuiper, G. G.; Enmark, E.; Pelto-Huikko M.; Nilsson, S.; Gustafsson, J.-A. Cloning of a novel receptor expressed in rat prostate and ovary. Proc. Natl. Acad. Sci. U.S.A. 1996, 93, 5925-5930.

4. Mosselman, S.; Polman, J.; Dijlkema, R. ER- $\beta$ : Identification and characterization of a novel human estrogen receptor. FEBS Lett. 1996, 392, 49-53.

5. Brandenberger, A. W.; Tee, M. K.; Lee, J. Y.; Chao, V.; Jaffe, R. B. Tissue distribution of estrogen receptors $\beta$ (ER- $\alpha$ ) and $\beta$ $($ ER- $\beta)$ mRNA in the midgestational human fetus. J. Clin. Endocrinol. Metab. 1997, 82, 3509-3512.

6. Gustafsson, J.-A. Estrogen receptor $\beta-\mathrm{A}$ new dimension in estrogen mechanism of action. J. Endocrinol. 1999, 163, 370383.

7. Brosage, P. Hormone therapy: The woman's decision. Contemp. Nurse. Pract. 1995, 1(S), 3.

8. Colditz, G. A.; Hankinson, S. E.; Hunter, D. J.; Willett, W. C.; Manson, J. E.; Stamper, M. J.; Hennekens, C.; Rosner, B.; Speizer, F. E. The use of estrogens and progestins and the risk of breast cancer in postmenopausal women. New Engl. J. Med. 1995, 332, 1589-1593.

9. Grodstein, F.; Stamfer, M. J.; Colditz, G. A.; Willett, W. C.; Manson, J. E.; Joffe, M.; Rosner, B.; Fuchs, C.; Hankinson, S. E.; Hunter, D. J.; Hennekens, C. H.; Speizer, F. E. Postmenopausal hormone therapy and mortality. New Engl. J. Med. 1997, 336, $1769-1775$.

10. Lupulescu, A. Estrogen use and cancer incidence: A review. Cancer Invest. 1995, 13, 287-295.

11. Bolton, J. L.; Pisha, E.; Zhang, F.; Qiu, S. Role of quinoids in estrogen carcinogenesis. Chem. Res. Toxicol. 1998, 11, 11131127.

12. Liehr, J. G. Is estradiol a genotoxic mutagenic carcinogen? Endocrine Rev. 2000, 21, 40-54.

13. Anderson, G. L.; Limacher, M.; Assaf, A. R.; Bassford, T.; Beresford, S. A.; Black, H.; Bonds, D.; Brunner, R.; Brzyski, R.; Caan, B.; Chlebowski, R.; Curb, D.; Gass, M.; Hays, J.; Heiss, G.; Hendrix, S.; Howard, B. V.; Hsia, J.; Hubbell, A.; Jackson, R.; Johnson, K. C.; Judd, H.; Kotchen, J. M.; Kuller, L.; LaCroix, A. Z.; Lane, D.; Langer, R. D.; Lasser, N.; Lewis, C. E.; Manson, J.; Margolis, K.; Ockene, J.; O'Sullivan, M. J.; Phillips, L.; Prentice, R. L.; Ritenbaugh, C.; Robbins, J.; Rossouw, J. E.; Sarto, G.; Stefanick, M. L.; Van Horn, L.; Wactawski-Wende, J.; Wallace, R.; Wassertheil-Smoller, S.; Women's Health Initiative Steering Committee. Effects of conjugated equine estrogen in postmenopausal women with hysterectomy: The Women's Health Initiative randomized controlled trial. JAMA 2004, 291, 1701-1712.

14. Espeland, M. A.; Rapp, S. R.; Shumaker, S. A.; Brunner, R.; Manson, J. E.; Sherwin, B. B.; Hsia, J.; Margolis, K. L.; Hogan, P. E.; Wallace, R.; Dailey, M.; Freeman, R.; Hays, J. Conjugated equine estrogens and global cognitive function in postmenopausal women: Women's Health Initiative Memory Study. JAMA 2004, 291, 2959-2968.

15. Lagana, A.; Bacaloni, A.; Fago, G.; Marino, A. Trace analysis of estrogenic chemicals in sewage effluent using liquid chroma- 
tography combined with tandem mass spectrometry. Rapid Commun. Mass Spectrom. 2000, 14, 401-407.

16. Croley, T. R.; Hughes, R. J.; Koenig, B. G.; Metcalfe, C. D.; March, R. E. Mass spectrometry applied to the analysis of estrogens in the environment. Rapid Commun. Mass Spectrom. 2000, 14, 1087-1093.

17. Devanesan, P.; Todorovic, R.; Zhao, J.; Gross, M. L.; Rogan, E. G.; Cavalieri E. L. Catechol estrogen conjugates and DNA adducts in the kidney of male Syrian golden hamsters treated with 4-hydroxyestradiol: Potential biomarkers for estrogeninitiated cancer. Carcinogenesis 2001, 22, 489-497.

18. Todorovic, R.; Devanesan, P; Higginbotham, S.; Zhao, J.; Gross, M. L.; Rogan, E. G.; Cavalieri, E. L. Analysis of potential biomarkers of estrogen-initiated cancer in the urine of Syrian golden hamsters treated with 4-hydroxyestradiol. Carcinogenesis 2001, 22, 905-911.

19. Draisci, R.; Palleschi, L.; Ferretti, E.; Marchiafava, C.; Lucentini, L.; Cammarata, P. Quantification of $17 \beta$-estradiol residues in bovine serum by liquid chromatography-tandem mass spectrometry with atmospheric pressure chemical ionization. Analyst 1998, 123, 2605-2609.

20. Baronti, C.; Curini, R.; D'Ascenzo, G.; Di Corcia, A.; Gentili, A.; Samperi, R. Monitoring natural and synthetic estrogens at activated sludge sewage treatment plants and in a receiving river water. Environ. Sci. Technol. 2000, 34, 5059-5066.

21. Huang, C. H.; Sedlak, D. L. Analysis of estrogenic hormones in municipal wastewater effluent and surface water using enzyme-linked immunosorbent assay and gas chromatography / tandem mass spectrometry. Environ. Toxicol. Chem. 2001, 20, 133-139.

22. Kelly, C. Analysis of steroids in environmental water samples using solid-phase extraction and ion-trap gas chromatography-mass spectrometry and gas chromatography-tandem mass spectrometry. J. Chromatogr. A 2000, 872, 309-314.

23. Shimada, K.; Mitamura, K.; Shiroyama, M.; Yago, K. Studies on neurosteroids. IX. Characterization of estrogens in rat brains using gas chromatography-tandem mass spectrometry. J. Chromatogr. A 1999, 847, 171-178.

24. Fournier, F.; Salles, C.; Tabet, J. C.; Debrauwer, L.; Rao, D.; Paris, A.; Borie, G. Tandem mass-spectrometric investigation on 17- $\beta$-estradiol palmitate in negative-ion chemical ionization. Anal. Chim. Acta 1999, 241, 265-272.

25. Ramanathan, R.; Cao, K.; Cavalieri, E.; Gross, M. L. Mass spectrometric methods for distinguishing structural isomers of glutathione conjugates of estrone and estradiol. J. Am. Soc. Mass Spec. 1998, 9, 612-619.

26. Embrechts, J.; Lemiere, F; van Dongen, W.; Esmans, E. L. Equilenin-2'-deoxynucleoside adducts: Analysis with nanoliquid chromatography coupled to nano-electrospray tandem mass spectrometry. J. Mass Spectrom. 2001, 36, 317-328.
27. van Breemen, R. B.; Huang, C.-R.; Nikolic, D.; Woodbury, C. P.; Zhao, Y.-Z.; Venton, D. L. Pulsed ultrafiltration mass spectrometry: A new method for screening combinatorial libraries. Anal. Chem. 1997, 69, 2159-2164.

28. Zhao, Y.-Z.; van Breemen, R. B.; Nikolic, D.; Huang, C.-R.; Woodbury, C. P.; Schilling, A.; Venton, D. L. Screening solution-phase combinatorial libraries using pulsed ultrafiltration/electrospray mass spectrometry. J. Med. Chem. 1997, 40, 4006-4012.

29. Nikolic, D.; van Breemen, R. B. Screening for inhibitors of dihydrofolate reductase using pulsed ultrafiltration mass spectrometry. Comb. Chem. High Throughput Screen. 1998, 1, $47-55$

30. Nikolic, D.; Habibi-Goudarzi, S.; Corley, D. G.; Gafner, S.; Pezzuto, J. M.; van Breemen, R. B. Evaluation of cyclooxygenase-2 inhibitors using pulsed ultrafiltration mass spectrometry. Anal. Chem. 2000, 72, 3853-3859.

31. Liu, J.; Burdette, J. E.; Xu, H.; Gu, C.; van Breemen, R. B.; Bhat, K. P. L.; Booth, N.; Constantinou, A. I.; Pezzuto, J. M.; Fong, H. H. S.; Farnsworth, N. R.; Bolton, J. L. Evaluation of estrogenic activity of plant extracts for the potential treatment of menopausal symptoms. J. Agric. Food Chem. 2001, 49, 2472-2479.

32. Obourn, J. D.; Koszewski, N. J.; Nortides, A. C. Hormone- and DNA-binding mechanisms of the recombinant human estrogen receptor. Biochemistry 1993, 32, 6229-6236.

33. Miksicek, R. J. Interaction of naturally occurring nonsteroidal estrogens with expressed recombinant human estrogen receptor. J. Steroid Biochem. Mol. Biol. 1994, 49, 153-160.

34. Kassel, D. B.; Conster, T. G.; Shalaby, M.; Sekhri, P.; Gordon, N.; Nadler, T. In Techniques in Protein Chemistry. VI; Crabb, J. W., Ed.; Academic Press: San Diego, CA, 1995; p 39.

35. Zuckermann, R. N.; Kerr, J. M.; Siani, M. A.; Banville, S. C.; Santi, D. V. Identification of highest-affinity ligands by affinity selection from equimolar peptide mixtures generated by robotic synthesis. Proc. Natl. Acad. Sci. U.S.A. 1992, 89, 4505.

36. Schumacher, T. N. M.; Mayr, L. M.; Minor, D. L., Jr.; Milhollen, M. A.; Burgess, M. W.; Kim, P. S. Identification of D-peptide ligands through mirror-image phage display. Science 1996, $274,1854-1857$.

37. Liang, R.; Yan, L.; Leobach, J.; Ge, M.; Uozumi, Y.; Sekanina, K.; Horan, N.; Gildersleeve, J.; Thompson, C.; Smith, A.; Biswas, K.; Still, W. C.; Kahne, D. Parallel synthesis and screening of a solid phase carbohydrate library. Science 1996, 274, 1520-1522.

38. Liu, X.; Yao, J.; Pisha, E.; Yang Y.; Hua, Y.; van Breemen, R. B.; Bolton, J. L. Oxidative DNA damage induced by equine estrogen metabolites: Role of estrogen receptor $\alpha$. Chem. Res. Toxicol. 2002, 15, 512-519. 